\title{
Genotype-Dependent Brown Adipose Tissue Activation in Patients With Pheochromocytoma and Paraganglioma
}

\author{
Citation for published version (APA):
}

Puar, T., van Berkel, A., Gotthardt, M., Havekes, B., Hermus, A. R., Lenders, J. W., van Marken Lichtenbelt, W. D., Xu, Y., Brans, R., \& Timmers, H. J. (2016). Genotype-Dependent Brown Adipose Tissue Activation in Patients With Pheochromocytoma and Paraganglioma. Journal of Clinical Endocrinology \& Metabolism, 101(1), 224-232. https://doi.org/10.1210/jc.2015-3205

\section{Document status and date: \\ Published: 01/01/2016}

DOI:

10.1210/jc.2015-3205

\section{Document Version:}

Publisher's PDF, also known as Version of record

\section{Document license:}

Taverne

\section{Please check the document version of this publication:}

- A submitted manuscript is the version of the article upon submission and before peer-review. There can be important differences between the submitted version and the official published version of record. People interested in the research are advised to contact the author for the final version of the publication, or visit the DOI to the publisher's website.

- The final author version and the galley proof are versions of the publication after peer review.

- The final published version features the final layout of the paper including the volume, issue and page numbers.

Link to publication

\footnotetext{
General rights rights.

- You may freely distribute the URL identifying the publication in the public portal. please follow below link for the End User Agreement:

www.umlib.nl/taverne-license

Take down policy

If you believe that this document breaches copyright please contact us at:

repository@maastrichtuniversity.nl

providing details and we will investigate your claim.
}

Copyright and moral rights for the publications made accessible in the public portal are retained by the authors and/or other copyright owners and it is a condition of accessing publications that users recognise and abide by the legal requirements associated with these

- Users may download and print one copy of any publication from the public portal for the purpose of private study or research.

- You may not further distribute the material or use it for any profit-making activity or commercial gain

If the publication is distributed under the terms of Article $25 \mathrm{fa}$ of the Dutch Copyright Act, indicated by the "Taverne" license above, 


\title{
Genotype-Dependent Brown Adipose Tissue Activation in Patients With Pheochromocytoma and Paraganglioma
}

\begin{abstract}
Troy Puar, Anouk van Berkel, Martin Gotthardt, Bas Havekes, Ad R. M. M. Hermus, Jacques W. M. Lenders, Wouter D. van Marken Lichtenbelt, Ying Xu, Boudewijn Brans, and Henri J. L. M. Timmers

Department of Internal Medicine (T.P., A.v.B., A.R.M.M.H., H.J.L.M.T.), Division of Endocrinology, Department of Radiology and Nuclear Medicine (M.G.), and Department of Internal Medicine (J.W.M.L.), Division of Vascular Medicine, Radboud University Medical Centre, 6500 HB Nijmegen, The Netherlands; Department of Endocrinology (T.P.), Changi General Hospital, Singapore 529889, Singapore; Department of Internal Medicine (B.H.), Division of Endocrinology, and Department of Human Biology (W.D.v.M.L.), NUTRIM School for Nutrition, Toxicology, and Metabolism, and Department of Medical Imaging (B.B.), Division of Nuclear Medicine, Maastricht University Medical Centre, 6202 AZ Maastricht, The Netherlands; Department of Medicine and Institute of Clinical Chemistry and Laboratory Medicine (J.W.M.L.), University Hospital Carl Gustav Carus, 01307 Dresden, Germany; and Centre for Quantitative Medicine (Y.X.), Duke-National University Singapore Graduate Medical School, Singapore 169856, Singapore
\end{abstract}

Context: Patients with pheochromocytomas and paragangliomas (PGLs) may have brown adipose tissue (BAT) activation induced by catecholamine excess. ${ }^{18} \mathrm{~F}$-fluorodeoxyglucose ( $\left.{ }^{18} \mathrm{~F}-\mathrm{FDG}\right)$ positron emission tomography (PET)/computed tomography (CT) can be used for the localization of both PGLs and BAT. It is unknown whether BAT is specifically affected by altered cellular energy metabolism in patients with $S D H x$ - and VHL-related PGLs.

Objective: The objective of the study was to determine endocrine and paracrine effects of catecholamine excess on BAT activation in patients with PGLs as detected by ${ }^{18} \mathrm{~F}-\mathrm{FDG}$ PET/CT, taking into account genetic variation.

Design: Patients with PGLs who were fully genetically characterized underwent presurgical ${ }^{18} \mathrm{~F}-$ FDG PET/CT imaging for tumor localization and to quantify BAT activation.

Setting: The study was conducted at a single Dutch tertiary referral center.

Patients and Intervention: Seventy-three patients, aged $52.4 \pm 15.4$ years, with a body mass index of $25.2 \pm 4.1 \mathrm{~kg} / \mathrm{m}^{2}$, mean $\pm \mathrm{SD}$, were grouped into sporadic, cluster $1(S D H x, V H L)$ and cluster 2 (RET, NF1, MAX) mutations.

Main Outcome Measures: ${ }^{18}$ F-FDG mean standard uptake values were assessed in predefined BAT locations, including perirenal fat.

Results: Twenty-one of 73 patients (28.8\%) exhibited BAT activation. BAT activation was absent in all six patients with nonsecreting PGLs. No difference in ${ }^{18} \mathrm{~F}-\mathrm{FDG}$ uptake by perirenal fat on the side of the pheochromocytoma and the contralateral side was observed (mean standard uptake value of 0.80 vs 0.78 , respectively, $P=.42$ ). The prevalence of BAT activation did not differ between sporadic $(28.9 \%)$, cluster $1(40.0 \%)$, and cluster 2 patients $(15.4 \%, P=.36)$.

Conclusion: Patients with PGLs exhibit a high prevalence of BAT activation on ${ }^{18} \mathrm{~F}$-FDG PET/CT. This is likely due to systemic catecholamine excess. BAT activation is not associated with specific germline mutations. (J Clin Endocrinol Metab 101: 224-232, 2016)

ISSN Print 0021-972X ISSN Online 1945-7197

Printed in USA

Copyright (C) 2016 by the Endocrine Society

Received August 19, 2015. Accepted November 5, 2015.

First Published Online November 17, 2015
Abbreviations: BAT, brown adipose tissue; BMI, body mass index; BRITE, brown in white; CT,
computed tomography; ${ }^{18} \mathrm{~F}-\mathrm{FDG},{ }^{18} \mathrm{~F}-$-fluorodeoxyglucose; MAX, myc-associated factor X; PET,
positron emission tomography; PGL, paragangliomas; RET, rearranged during transfection;
SDH, succinate dehydrogenase; SUV, standard uptake value; TMEM, transmembrane protein;
UCP1, uncoupling protein-1; VHL, von Hippel-Lindau; VOI, volume of interest. 
B rown adipose tissue (BAT) is present in infants and diminishes with age (1). Activation of BAT can be visualized using in vivo imaging with ${ }^{18} \mathrm{~F}$-fluorodeoxyglucose $\left({ }^{18} \mathrm{~F}-\mathrm{FDG}\right)$ positron emission tomography (PET)/ computed tomography $(\mathrm{CT})$ imaging and has led to the realization that remnants are still present in adulthood (2, $3)$. The role of BAT in metabolism and obesity has led to greater interest in the regulatory mechanisms of this tissue (4). It has been shown in animal studies that norepinephrine stimulation of BAT via $\beta 3$-receptors lead to increased number of brown fat cells, lipolysis, glucose transportation, expression of uncoupling protein-1 (UCP1), and ultimately heat production (5). In humans, systemic catecholamines may similarly play a role in stimulation of BAT.

Hypersecretion of catecholamines is the hallmark of pheochromocytomas and sympathetic paragangliomas (PGLs). PGLs are neuroendocrine tumors of the adrenal medulla and sympathetic paraganglia. In vivo cancer imaging with ${ }^{18}$ F-FDG PET/CT uses the characteristic of increased uptake of glucose and ${ }^{18}$ F-FDG by tumor cells, relative to normal cells. In patients with PGLs, activated BAT tissue is often visualized $(6,7)$, and it was present in up to $27 \%$ of patients when various functional imaging studies, including ${ }^{18}$ F-FDG PET/CT, were combined (8). The recruitment of BAT appears to be dynamic, with case reports of patients with PGLs demonstrating BAT activation in association with increased systemic catecholamine levels, whereas normalization of catecholamines after surgery subsequently led to a significant reduction of BAT activation $(9,10)$.

The classical depot of BAT is located interscapularly. In animal studies, chronic cold stimulation or $\beta$-adrenergic stimulation leads to brown adipocytes dispersed in white adipose tissue, which have been termed inducible brown adipocytes, brown in white (BRITE) or beige adipocytes. Whereas classical BAT cells are derived from a myf-5 cellular lineage (similar to skeletal muscle cells), beige adipocytes are derived from a myf-5-negative lineage (similar to white fat) (11). Recent studies on the BAT depots in the supraclavicular area in adults found predominantly BRITE adipocytes, with only some overlap with the classical BAT, demonstrating that it cannot be differentiated by anatomical location (12). Recently this coexistence of BRITE and classical BAT was found in the peritumoral fat surrounding a pheochromocytoma, whereas BAT was absent around nonfunctional adrenal adenomas, leading to suggestions that local catecholamines had a paracrine effect on the browning of peritumoral fat (13). Because the kidneys and the adrenal glands are encapsulated by a common connective tissue (Gerota's fascia), we hypothesized that local catecholamine secretion and action from the
PGLs might lead to an increased BAT activation in the adjacent perirenal fat.

Up to $40 \%$ of PGLs are caused by germline mutations in tumor susceptibility genes, including von HippelLindau ( VHL), succinate dehydrogenase subunits A, B, C, and $\mathrm{D}$, and assembly factor 2 (SDHA/B/C/D/AF2), neurofibromatosis type 1 (NF1), rearranged during transfection (RET), myc-associated factor $\mathrm{X}(M A X)$ and transmembrane protein (TMEM127) (14). Based on gene expression profiling, PGLs can be classified into cluster 1 (VHL, SDHx) with increased expression of genes associated with angiogenesis and hypoxia, and cluster 2 (RET, NF1, MAX, TMEM127) with increased expression of genes associated with RNA synthesis and kinase signaling $(15,16)$.

SDHx mutations cause impairment of succinate dehydrogenase $(\mathrm{SDH})$ function in the mitochondria electron transport chain and hence compromise oxidative phosphorylation (16-18). Similarly, VHL-related PGLs mutations also have impaired oxidative phosphorylation (19). This results in activation of the hypoxic-angiogenic pathway via transcription factors hypoxia-inducible factors (types $1 \alpha$ and $2 \alpha$ ) (20). Their main target genes include genes involved in glucose metabolism such as glucose transporters, hexokinases, and angiogenesis (vascular endothelial growth factor) as well as survival and motility (21). ${ }^{18}$ F-FDG uptake varies among PGLs of different genotypes, with the highest standard uptake values (SUVs) observed in PGLs belonging to cluster 1 (22). Because these are germline mutations, there is potential to affect all cells with mitochondria, including BAT, which contains abundant mitochondria.

The aims of this study were to determine the systemic and paracrine effects of excess catecholamine secretion by PGLs on BAT and to determine whether specific germline mutations were associated with BAT activation in patients with PGLs.

\section{Materials and Methods}

\section{Patient population}

Seventy-three consecutive patients (aged $52.4 \pm 15.4$ y, body mass index (BMI) $25.2 \pm 4.1 \mathrm{~kg} / \mathrm{m}^{2}$, mean $\pm \mathrm{SD}, 40$ men and 33 women) with a confirmed PGL who had undergone an ${ }^{18} \mathrm{~F}-\mathrm{FDG}$ PET/CT scan between December 2007 and February 2015 were studied. Sixty tumors $(82.2 \%)$ were adrenal, two $(2.7 \%)$ extraadrenal, and $11(15.1 \%)$ metastatic PGLs. Seventy-two patients had histological confirmation of a PGL, whereas one patient had metastatic PGL as proven by extreme elevations of metanephrines and typical imaging features. Collection of plasma metanephrines were collected under strict clinical protocol (23), and they were measured using liquid chromatography with electrochemical detection (24). All patients had undergone genetic test- 
ing for germline mutations in known susceptibility genes. Fortyfive patients had sporadic tumors, 15 patients belonged in cluster 1 (SDHA, $\mathrm{n}=2 ; S D H B, \mathrm{n}=5, S D H D, \mathrm{n}=7, V H L, \mathrm{n}=1)$, and 13 patients belonged to cluster $2(R E T, \mathrm{n}=8 ; N F 1, \mathrm{n}=4 ; M A X$, $\mathrm{n}=1$ ). Six patients had nonfunctional PGLs (with consistently normal plasma metanephrines levels), of whom one was sporadic, and the remaining five belonged to cluster $1(S D H B, \mathrm{n}=$ 2; SDHD, $\mathrm{n}=3$ ) (Table 1). Data were collected under conditions of regular clinical care, with the approval of ethics committee obtained for the retrospective use of those data, for scientific purposes. All patients consented in the use of their clinical data.

\section{Imaging procedures}

Our ${ }^{18}$ F-FDG PET/CT scanning protocol has been previously described (25). After the injection of ${ }^{18} \mathrm{~F}-\mathrm{FDG}$, patients sat for 60 minutes in a quiet room in which the ambient temperature was set at $20^{\circ} \mathrm{C}$. Subjects were neither warmed nor instructed to avoid cold before the PET/CT examinations. Data on age, sex, height, weight, fasting plasma glucose level, and use of $\beta$-blockers and $\alpha$-blockers were obtained for all patients. Outdoor temperatures were registered to account for seasonal differences based on data from the Royal Netherlands Meteorological Institution.

\section{Image interpretation and quantitative measurements}

${ }^{18}$ F-FDG PET/CT images were reviewed using Inveon Research Workplace software (version 4.1; Siemens Healthcare). Both the researcher (T.P.) and a nuclear medicine physician (B.B.) interpreted the images. Classical sites of BAT activation were assessed, which included cervical, supraclavicular, axillary, mediastinal, pericardial, periaortal, and perirenal tissue. BAT activation was deemed present if there was increased uptake of ${ }^{18}$ F-FDG, identified by a maximum standardized uptake value $\left(\mathrm{SUV}_{\max }\right.$ ) greater than 1.5 on PET (approximately 6 times higher than in white adipose tissue), and it corresponded to an area of fat on CT (Hounsfield units: -10 to -180 ) (26). A volume of interest (VOI) was then drawn up in the area of maximal uptake (Figure 1), with a fixed cubic size of $8 \times 8 \times 8 \mathrm{~mm}$ (total volume $1.014 \mathrm{~mm}^{3}$ ) and used for quantitative analysis.

Regardless of the presence of BAT activation, VOIs were also drawn in several sites in all patients: bilateral supraclavicular fat (representing typical BAT site), sc abdominal fat (representing typical white adipose tissue site), and bilateral perirenal fat (representing possible site of BRITE fat). In the perirenal fat, VOIs were drawn up bilaterally at three levels: upper third, middle third, and lower third relative to the kidneys. The average of the three levels was then taken for each side. In patients with perirenal fat volume that was less than the VOI $(8 \times 8 \times 8 \mathrm{~mm})$, this could not be assessed. Maximum and mean standardized uptake values $\left(\mathrm{SUV}_{\text {max }}\right.$ and $\mathrm{SUV}_{\text {mean }}$ ) were established in all VOIs. SU$\mathrm{V}_{\text {max }}$ of tumors were also measured as previously described (25). They were normalized for body weight and were calculated as $\mathrm{SUV}=\mathrm{A} / \mathrm{IA} \times \mathrm{BW}(\mathrm{A}$, activity concentration of VOI [bequerels per milliliter]; BS, body weight [grams]; IA, injected activity [bequerels]). All calculated SUVs were decay corrected using the following formula: $A_{0}=A_{t} \times e^{\lambda t}\left(A_{0}\right.$, corrected activity; $A_{t}$, uncorrected activity; $\lambda$, decay constant $[\operatorname{In} 2 / 11]$ minutes $^{-1}$; $t$, elapsed time in minutes).

\section{Statistical analysis}

Baseline characteristics were presented in mean \pm SD for continuous variables and number (percentage) for categorical variables. Kruskal-Wallis test with post hoc Dunn test for continuous variables and Fisher's exact test for categorical variables were used to compare the baseline characteristics between the mutation groups. Wilcoxon rank-sum test and Fisher's exact tests were used to compare between BAT patients and non-BAT patients to assess for risk factors for BAT activation.

Table 1. Baseline Characteristics of Patients by Mutation Group $(n=73)$

\begin{tabular}{|c|c|c|c|c|c|}
\hline & $\begin{array}{l}\text { Sporadic } \\
(\mathrm{n}=45)^{\mathrm{a}}\end{array}$ & $\begin{array}{l}\text { Cluster } 1 \\
(n=15)^{b}\end{array}$ & $\begin{array}{l}\text { Cluster } 2 \\
(n=13)^{c}\end{array}$ & $\begin{array}{l}\text { Total } \\
(n=73)\end{array}$ & $\boldsymbol{P}$ \\
\hline Age, y & $56.0 \pm 13.9$ & $44.2 \pm 16.8$ & $49.7 \pm 15.8$ & $52.4 \pm 15.4$ & $.03^{d}$ \\
\hline $\mathrm{BMI}, \mathrm{kg} / \mathrm{m}^{2}$ & $25.2 \pm 4.3$ & $25.5 \pm 4.1$ & $24.7 \pm 3.6$ & $25.2 \pm 4.1$ & .96 \\
\hline$\beta$-Blocker use, \% & $16(35.6)$ & $3(20.0)$ & $2(15.4)$ & $21(28.8)$ & .33 \\
\hline$\alpha$-Blocker use, $\%$ & $31(68.9)$ & $7(46.7)$ & $7(53.8)$ & $45(61.6)$ & .25 \\
\hline Diabetes mellitus, \% & $8(17.8)$ & $1(6.7)$ & $1(7.7)$ & $10(13.7)$ & .56 \\
\hline Plasma normetanephrine, $48-495 \mathrm{pmol} / \mathrm{L}$ & $10028 \pm 16123$ & $8419 \pm 14347$ & $3477 \pm 5666$ & $8532 \pm 14500$ & .17 \\
\hline Plasma metanephrine, 57-295 pmol/L & $2658 \pm 3313$ & $195 \pm 92$ & $1540 \pm 2166$ & $1953 \pm 2912$ & $<.001^{\epsilon}$ \\
\hline Nonfunctional, \% & $1(2.2)$ & $5(33.3)$ & $0(0.0)$ & $6(8.2)$ & $<.001$ \\
\hline
\end{tabular}

Abbreviations: A, adrenal; E, extraadrenal; $M$, metastatic disease. Results are presented as mean \pm SD unless stated. $P$ value shown in the last column are from a Kruskal-Wallis test for comparing the three groups if the variable is continuous and Fisher's exact test if the variable is categorical.

a Patients were tested for the presence of germline mutations and large deletions in SDHB/CID, RET, VHL, and since 2011, in SDHA, SDHAF2, TMEM 127, and MAX.

b Patients with germline mutations in succinate dehydrogenase subunits $A, B, C$, and D and assembly factor 2 (SDHA/B/C/D/AF2), and von HippelLindau (VHL).

c Patients with germline mutations in neurofibromatosis type 1 (NF1), rearranged during transfection (RET), myc-associated factor X (MAX), and transmembrane protein (TMEM127).

${ }^{\mathrm{d}} P=.02$ between cluster 1 and sporadic.

e $P<.001$ between cluster 1 and sporadic, $P=.003$ between cluster 1 and cluster 2 . 


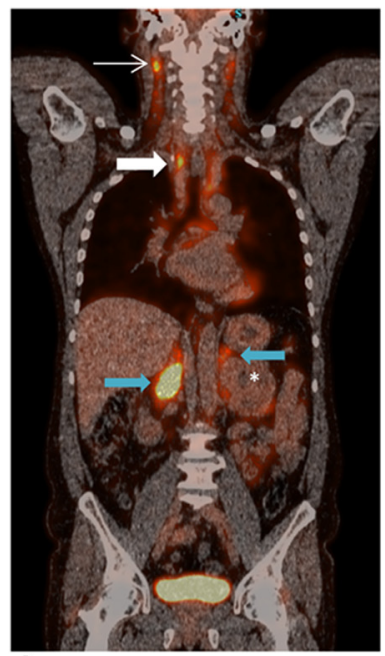

A

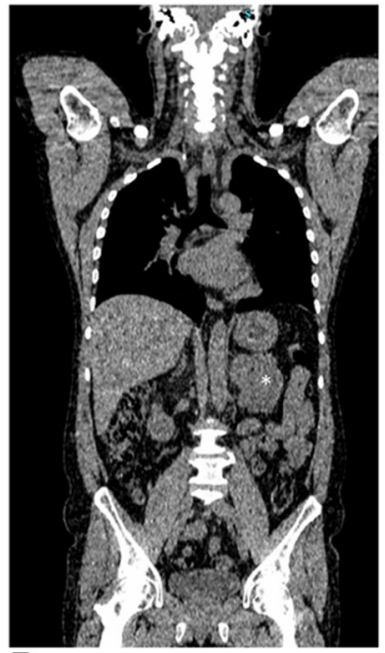

B

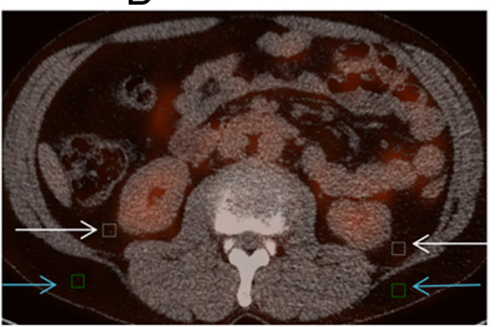

G

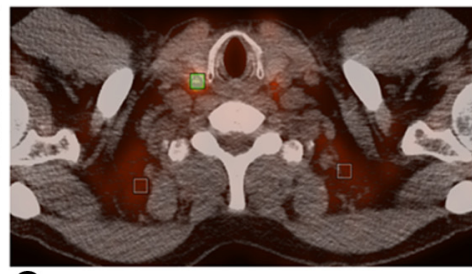

C

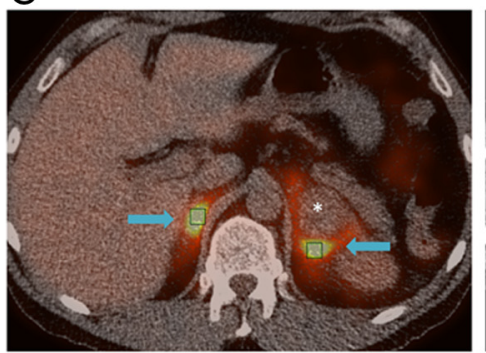

E

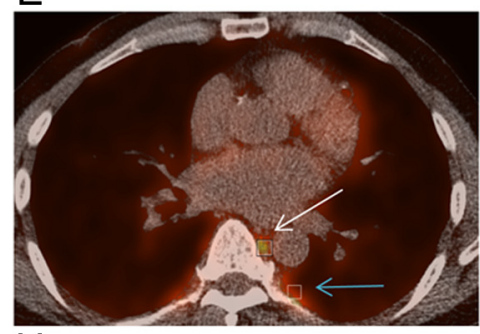

$\mathrm{H}$

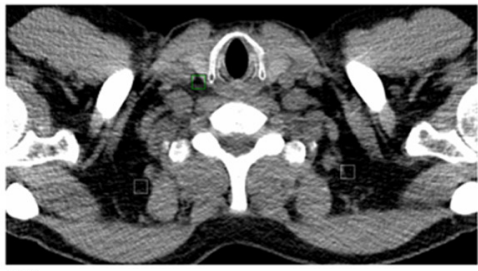

D

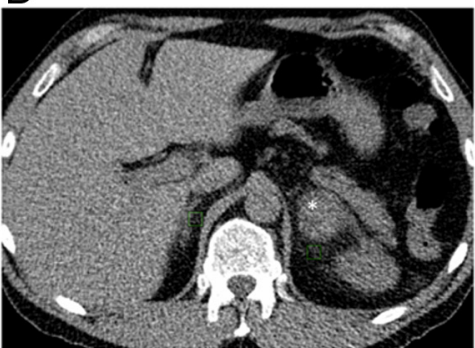

F

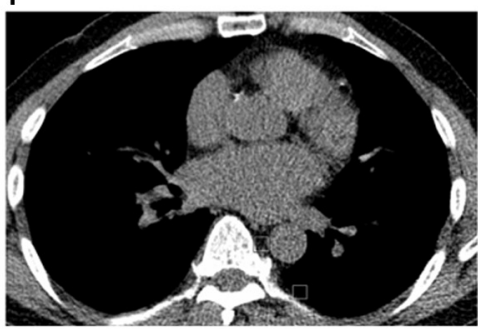

Figure 1. A 55-year-old man with left sporadic pheochromocytoma and BAT activation. A and B, Coronal PET/CT fusion (A) and coronal CT (B) images show increased uptake of ${ }^{18} \mathrm{~F}-\mathrm{FDG}$ activity mapped to areas of fat density among neck (thin white arrow) and mediastinum (thick white arrow). Uptake is greater in contralateral (right) perirenal fat (blue arrows) compared with the ipsilateral (left) side surrounding the tumor (*). $C$ and D, Transversal PET/CT fusion (C) and CT (D) images show mildly increased uptake of ${ }^{18} \mathrm{~F}-\mathrm{FDG}$ activity in bilateral supraclavicular areas, with VOls drawn (white boxes). E and F, Transversal PET/CT fusion (E) and CT (F) images show increased uptake of ${ }^{18}$ F-FDG activity in perirenal areas (blue arrows), with activity greater on the contralateral side of the tumor (*). G, Transversal PET/CT fusion images showing VOls of perirenal fat (white arrows) and sc fat (blue arrows) (I). H and I, Transversal PET/CT fusion (H) and CT (I) images show BAT activation in periaortal (white arrow) and perivertebral (blue arrow) sites.

In patients with a functioning unilateral tumor, we assessed for a paracrine effect of a tumor stimulating BAT activation in the surrounding fat, by comparing the average perirenal VOIs ipsilateral to the tumor with the contralateral side, using a Wilcoxon matched-pairs signed-ranks test.

For comparison of SUVs of different genotypes, the SUV (supraclavicular), $\mathrm{SUV}_{\text {mean }}$ (abdominal fat), and $\mathrm{SUV}_{\text {mean }}$ (perirenal fat) were analyzed using Kruskal-Wallis test with the post hoc Dunn test along with $\mathrm{SUV}_{\text {max }}$ (tumor) and $\mathrm{SUV}_{\max }$ (of the most active BAT site). The presence of BAT activity was analyzed in the functional and nonfunctional groups and the genotype clusters, using Fisher's exact test. All statistical computations were performed with STATA version 12.1 (StataCorp LP). Figures were produced with GraphPad Prism version 5.0 for Windows (GraphPad Software). All tests will be two tailed with significance set at $P<.05$.

\section{Results}

\section{Systemic catecholamines and BAT activation}

Overall, 21 of 73 patients $(28.8 \%)$ had BAT activation (Supplemental Table 1). Twenty-one of 67 functional tu- mors $(31.3 \%)$ had BAT activation, compared with none of the six patients with nonfunctioning tumors $(P=.17)$. Patients with BAT activation were significantly younger when compared with patients without BAT activation (age $41.4 \pm 14.6$ y vs $56.9 \pm 13.5$ y $[P<.001]$ ), whereas there was a trend towards a lower BMI and lower outdoor temperature (Table 2). However, levels of normetanephrine and metanephrine, the metabolites of norepinephrine and epinephrine, respectively, did not significantly differ between both groups $(11974 \pm 17125 \mathrm{pmol} / \mathrm{L}$ vs $7140 \pm$ $13227 \mathrm{pmol} / \mathrm{L}, \mathrm{P}=.24$, and $1778 \pm 3471 \mathrm{pmol} / \mathrm{L}$ vs $2024 \pm 2688 \mathrm{pmol} / \mathrm{L}, P=.19)$. A total of $28.8 \%$ of patients were using $\beta$-blockers at the time of the scan, and there was no difference between those with and without BAT activation. In a subgroup analysis looking only at patients without prior $\beta$-blockers use, there was a trend toward patients with BAT activation having a higher plasma normetanephrine level compared with those without activation, although this did not reach statistical significance $(9801 \pm 15434 \mathrm{pmol} / \mathrm{L}$ and $3362 \pm 4481$ $\mathrm{pmol} / \mathrm{L}, P=.09)$. 
Table 2. Patients With BAT Activation Compared With Patients Without BAT Activation

\begin{tabular}{llll}
\hline & $\begin{array}{l}\text { BAT Activation } \\
(\mathbf{n}=\mathbf{2 1})\end{array}$ & $\begin{array}{l}\text { No BAT Activation } \\
(\mathbf{n}=\mathbf{5 2})\end{array}$ & $\mathbf{P}$ \\
\hline Age, $\mathrm{y}$ & $41.4 \pm 14.6$ & $56.9 \pm 13.5$ & $<.001$ \\
Sex, females, \% & $10(47.6)$ & $23(44.2)$ & .80 \\
BMl, kg/m ${ }^{2}$ & $24.0 \pm 3.6$ & $25.7 \pm 4.3$ & .06 \\
$\beta$-Blocker use, \% & $5(23.8)$ & $16(30.8)$ & .78 \\
$\alpha$-Blocker use, \% & $13(61.9)$ & $32(61.5)$ & 1.00 \\
Diabetes mellitus, \% & $2(9.5)$ & $8(15.4)$ & .71 \\
Outdoor T, ${ }^{\circ} \mathrm{C}$ & $7.6 \pm 7.9$ & $10.5 \pm 6.3$ & .14 \\
Serum glucose, mmol/L & $5.8 \pm 1.2$ & $6.0 \pm 1.3$ & .72 \\
Plasma normetanephrine, 48-495 pmol/L & $11974 \pm 17125$ & $7140 \pm 13227$ & .24 \\
Plasma metanephrine, 57-295 pmol/L & $1778 \pm 3471$ & $2024 \pm 2688$ & .19 \\
\hline
\end{tabular}

Abbreviation: T, temperature. Results presented as mean \pm SD unless otherwise stated. The $P$ values shown in the last column are from a Wilcoxon rank-sum test for comparing the two groups if the variable is continuous and Fisher's exact test if the variable is categorical.

The supraclavicular area was the most frequent site in which BAT activation was found, in 18 of the 21 patients $(85.7 \%)$ with BAT activation. The next most common sites were neck, mediastinum, and perivertebral areas, with detection in 14 patients $(66.7 \%)$, whereas perirenal activation was noted in six patients $(28.6 \%)$.

\section{Paracrine effects of catecholamines on BAT}

Among the 73 patients, we excluded 18 patients with inadequate perirenal fat for assessment, six with nonfunctional tumors and five with bilateral or nonadrenal tumors. The remaining 44 patients had unilateral, functional pheochromocytomas and were assessed for BAT activation of perirenal fat as a reflection of paracrine effects of locally released catecholamines. The mean ipsilateral perirenal SUV $\mathrm{S}_{\text {mean }}$ did not significantly differ from the contralateral side $(0.78 \pm 0.77$ vs $0.80 \pm 0.86, P=.32)$. Twenty-five patients had a higher $\mathrm{SUV}_{\text {mean }}$ on the contralateral side, compared with 19 patients with higher SU$\mathrm{V}_{\text {mean }}$ on the ipsilateral side (Figure 2).

\section{BAT activation across different genotypes}

BAT activation was observed in 13 of 45 patients with sporadic tumors $(28.9 \%), 6$ of 15 in cluster 1 patients $(40.0 \%)$, and 2 of 13 in cluster 2 patients $(15.4 \%, P=$ .36). The mean $S_{U} V_{\max }$ of the tumors in cluster 1 was significantly higher than both sporadic and cluster 2 tumors $(18.5 \pm 9.2$ vs $5.8 \pm 4.6$ and $3.8 \pm 1.5, P<.001)$ (Figure 3). However, no statistical difference was found in the $\mathrm{SUV}_{\max }$ of the most active BAT site between these groups ( $3.7 \pm 5.7$ vs $1.6 \pm 2.2$ vs $1.5 \pm 2.9$, respectively, $P=.26)$. Similarly, in the supraclavicular, sc, and perirenal sites, $\mathrm{SUV}_{\text {mean }}$ was similar in all groups (Figure 3 ). Between the mutation groups, there was no significant difference in the number of BAT sites that were noted among patients with BAT activation $(4.5 \pm 1.9$ vs $6.2 \pm$ 2.1 vs $5.0 \pm 2.8, P=.26$ ).

\section{Discussion}

This is the first study to date of fully genetically characterized patients with PGLs, looking to examine the effects of genotype differences on the activation of brown fat using ${ }^{18}$ F-FDG PET/CT imaging. Although significantly higher FDG uptake was detected in tumors of patients with cluster 1 mutations compared with those with cluster

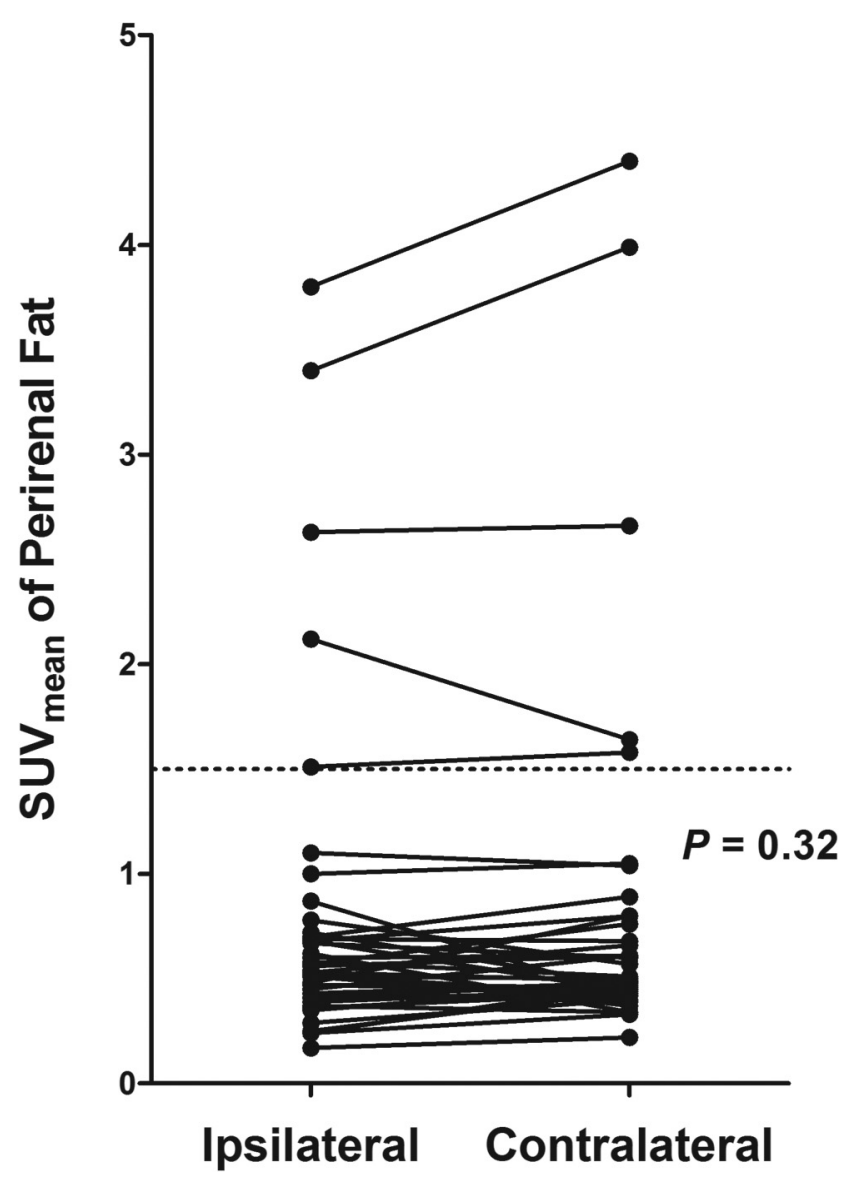

Figure 2. Comparing SUV $V_{\text {mean }}$ of perirenal fat on ipsilateral side of pheochromocytoma to contralateral perirenal fat in 44 patients with a functional unilateral pheochromocytoma. 

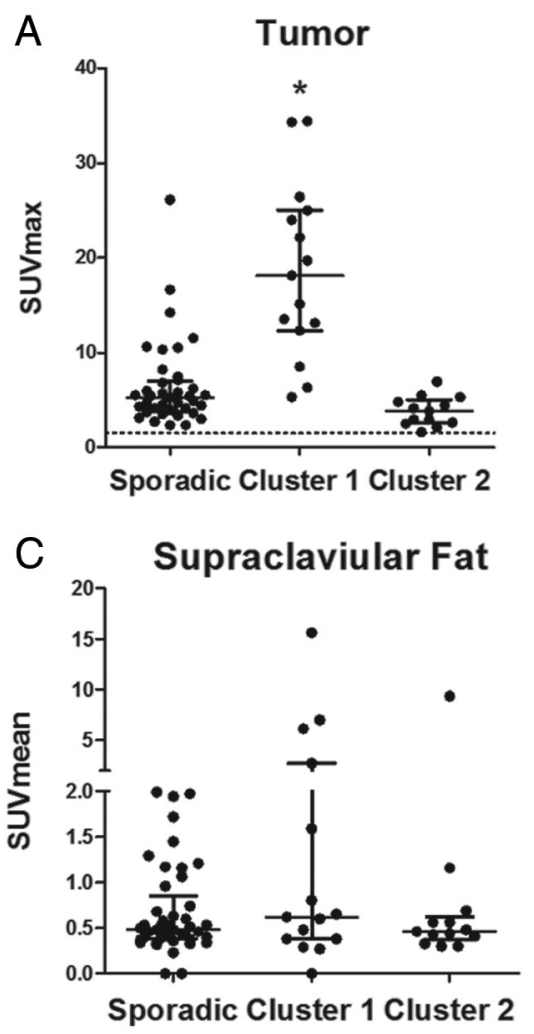
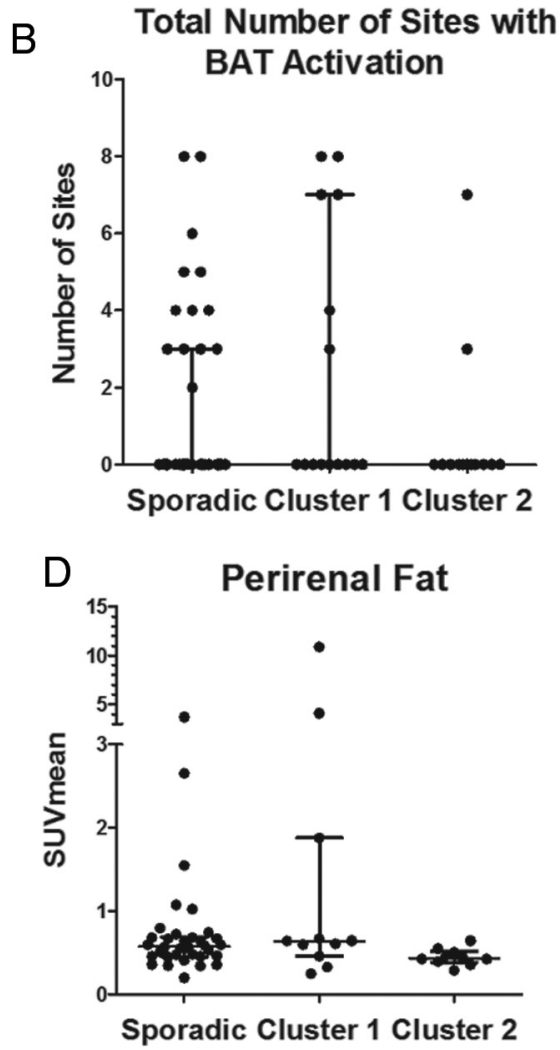

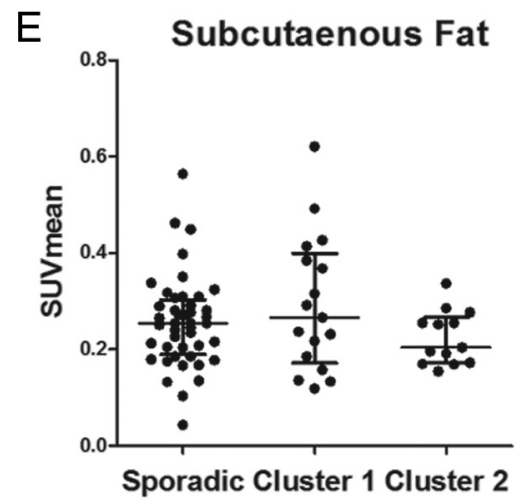

Figure 3. Median ( \pm interquartile range) uptake of ${ }^{18} \mathrm{~F}-\mathrm{FDG}$ in various tissues in patients with sporadic PGLS, Cluster 1 (SDHA, SDHB, SDHD, VHL) and cluster $2(R E T, N F 1, M A X)$ mutations. A, SUV $\max$ of tumor. * ${ }^{*} S_{\text {SUV }} \max$ greater in cluster 1 compared with sporadic tumors $(P<.001)$. B, Total number of sites with BAT activation (areas assessed were cervical, supraclavicular, axillary, mediastinal, pericardial, periaortal, and perirenal). C, SUV $_{\text {mean }}$ at supraclavicular area (classical BAT site). D, SUV mean at perirenal fat (possible brown to white adipose site). E, SUV $V_{\text {mean }}$ at SC fat (white adipose tissue).

2 mutations or sporadic, there was no difference in BAT activity between the groups in terms of BAT prevalence and ${ }^{18}$ F-FDG uptake at various BAT sites. Local release of catecholamines from a tumor do not appear to lead to increased BAT activation in the adjacent perirenal fat because the activity on the ipsilateral side was not greater than the contralateral side. At the same time, we confirmed a high proportion of patients with PGLs $(28.8 \%)$ with BAT activation, which is much higher than the prevalence of $3 \%-7 \%$ reported in general adult population studies (27). BAT activation was not present in patients with nonfunctional tumors.

\section{Systemic effects of catecholamines}

In a previous large study by Hadi et al (8) in patients with PGLs, BAT activation was noted on ${ }^{18} \mathrm{~F}-\mathrm{FDG}$ $\mathrm{PET} / \mathrm{CT}$ in a similar proportion of patients with confirmed PGLs (13 of 59, 22\%). They found a mean SUV $\mathrm{Smax}_{\max }$ of the BAT tissue of 3.9, similar to ours of 4.0, which is well above the PET activity of normal fat. Age is often considered the strongest determinant for BAT activation (28), and this was confirmed by our study. There was a trend toward colder outdoor temperature and lower BMI in- creasing BAT activation, which are well described factors (29)

BAT activation was detected only in patients with functional tumors and in none of the patients with nonfunctional tumors. This is similar to a previous study showing BAT activation only in patients with functional PGLs but not in 20 patients or subjects with normal metanephrines levels (30). This supports the role of systemic catecholamines in BAT activation. Hadi et al (8) found higher mean norepinephrine levels in BAT activation. We could not confirm an association between normetanephrine levels and BAT activation. There could be several explanations for this, such as the use of $\beta$-blockers by patients in the current study. Also, down-regulation of catecholamine receptors has been known to occur in patients with functional PGLs, limiting the effects of catecholamine excess, and this may occur similarly in BAT (31).

\section{Local effects of catecholamines}

Local effects of catecholamines may be relevant because a recent study demonstrated induction of brown fat around a pheochromocytoma, suggesting that the local catecholamine release from the tumor may stimulate local 
depots of adipose tissue (13). Humans, similar to rodents, have two types of brown adipocytes, classical and BRITE (11). Using cell-specific markers, both classical and BRITE BAT in the adipose tissue surrounding the tumor were identified. This coexistence of both brown adipocytes has also been shown in supraclavicular fat (12) and highlights the difficulty in differentiating the two depots, using cell markers with currently undefined cell functions (32). The importance of distinction between the two types is that they may be stimulated and recruited by different signals (4).

This finding led us to look for evidence of perirenal fat being stimulated by the local catecholamines released from an adjacent pheochromocytoma. Nevertheless, there was no difference between the SUV $\mathrm{V}_{\text {mean }}$ of the perirenal fat on the ipsilateral side of the tumor compared with the contralateral side. A plausible explanation would be that some of these pheochromocytomas have only mild catecholamine excess. On the other hand, even in a subgroup of patients with at least 10 times the elevation of plasma normetanephrines $(\mathrm{n}=16)$, the findings were similar, with mean $S_{U V}$ mean of the ipsilateral perirenal fat not greater than the contralateral side $(1.12 \pm 1.13$ vs $1.19 \pm$ $1.27, P=.28$ ).

Of the 21 patients with BAT activation, six (28.6\%) demonstrated perirenal BAT activation, similar to another study that had a prevalence of $26.3 \%$ (29). In these six patients, the perirenal site was the site of greatest BAT activity (highest $S_{U V} V_{\max }$ ) in two patients, of whom one patient had a metastatic bladder paraganglioma, and high perirenal BAT activation could not be attributed to local hormonal release.

It is still possible that perirenal BAT activation is often present around a pheochromocytoma, as previously suggested (13), because PET may underestimate BAT activity (33). Tissue measurements of UCP1, a specific marker for brown adipocytes, can detect smaller quantities of BAT and probably is more sensitive (5). However, PET is able to reflect the quantity of BAT tissue, and only one of these six patients with perirenal BAT had increased activity of perirenal fat on the ipsilateral side of the tumor. It is also worthwhile to note that in addition to paracrine effects of a tumor, if any, all patients were also exposed to the systemic effects of catecholamine excess, and this study was not able to distinguish the effects of the two. Taken together, we could not confirm previous suggestions of the browning of perirenal fat from paracrine effects of a pheochromocytoma.

\section{Germline mitochondrial mutations and BAT activity}

SDH genes are nuclear genes encoding for mitochondrial proteins, and they act as tumor suppressors. In PGL tumors, $S D H x$ mutations result in defects in the mitochondrial oxidation pathway, accumulation of succinate, stabilization of the hypoxia-inducible factor pathway, and tumorigenesis via the Warburg effect (34). Although this is a germline mutation, patients with $S D H x$ mutations do not appear to exhibit increased propensity to tumors in other tissues, leading to the hypothesis that a second hit is required (35). The sympathetic ganglia and adrenal medulla appear to be more vulnerable to tumor development, possibly due to their oxygen sensing properties. BAT, which contains abundant mitochondria, offers a possibility to examine for altered energy metabolism in nontumoral tissue of patients with PGLs and germline mutations.

${ }^{18} \mathrm{~F}-\mathrm{FDG}$ uptake was greater in cluster 1 tumors, consistent with prior findings, and we previously identified that this is due to accelerated glucose phosphorylation by hexokinases and not increased glucose transporter expression (25). In contrast, there was no significant difference between the mutation groups, in terms of prevalence of BAT activation, number of sites, or intensity of BAT (SU$\left.\mathrm{V}_{\max }\right)$. Furthermore, in predefined VOIs of the supraclavicular, perirenal, and sc fat, there was no significant difference in $\mathrm{SUV}_{\text {mean }}$ in the different clusters. Patients with cluster 1 mutations were younger than patients with sporadic tumors, which is expected because it is an inherited condition. Despite this, there was still no increase in prevalence of BAT activation in patients with cluster 1 mutations.

One possible explanation is that although there is loss of heterozygosity in SDHx-related PGLs, germline mutations are present in only one allele in nontumoral cells and might therefore not affect mitochondrial function. This might explain lack of BAT activation. Another possibility is that ${ }^{18} \mathrm{~F}$-FDG PET/CT visualizes only glucose uptake and not free fatty acids, which is a major substrate of BAT (36). A third possible explanation is that UCP1 in BAT uncouples the normal respiratory chain by using the proton gradient across the mitochondrial membrane to generate heat instead of ATP production. Although we expect that $S D H$ functional loss may lead to induction of hypoxic pathways and increased glucose consumption, it is also possible, that because UCP1 generates heat from the proton gradient, $S D H x$ mutations that lead to impairment of mitochondrial complex II, as evidenced by lower complex II activity and lower ATP/ADP/AMP content (18), may reduce the proton gradient generated and hence lead to lower BAT activity.

There are several limitations in this study. Being a retrospective study, we did not control for confounders such as outdoor temperature or medication use. However, scanning condition was standardized and we collected in- 
formation with regard to these possible confounders. Use of $\beta$-blockers may reduce BAT activation (37). However, this should lower only the prevalence or activity of BAT detected on PET and lead to an underestimation, whereas we found a high prevalence of BAT activation. Also, $\beta$-blocker use was equally distributed among the genetic mutation groups. Using a single VOI to measure the SU$\mathrm{V}_{\text {mean }}$ or $\mathrm{SUV}_{\text {max }}$ of various sites of BAT activation may underestimate the true volume of BAT tissue in that particular site. However, there is currently no agreed universal method to quantify BAT activity on PET (26). Hence, we ensured that we consistently used the same standardized method among all patients. We acknowledge that no control population was available, but our main focus was to study paracrine and genetic effects.

\section{Conclusion}

Significant BAT activation can be detected in up to $30 \%$ of patients with PGLs. This is likely to be due to systemic effects of catecholamine excess. We could not confirm a paracrine effect of catecholamine secretion by pheochromocytomas on perirenal BAT activation. However, ${ }^{18} \mathrm{~F}-$ FDG PET/CT might not be the most sensitive tool to detect such an effect, and paracrine effects may be superseded by systemic catecholamine effects. Furthermore, germline SDHx mutations appear to play no role in systemic BAT activation, although this awaits further investigations on a molecular level.

\section{Acknowledgments}

We thank Patrick Schrauwen (Department of Human Biology, NUTRIM School for Nutrition, Toxicology, and Metabolism, Maastricht University Medical Centre) for his expertise and input in the manuscript.

Address all correspondence and requests for reprints to: Troy Puar, MBBS, Department of Internal Medicine, Division of Endocrinology, Radboud University Medical Centre, 6500 HB Nijmegen, The Netherlands. E-mail: troy_puar@cgh.com.sg.

This work was supported by the European Union Seventh Framework Program (FP7/2007-2013) under Grant Agreement 259735 (ENSAT CANCER).

Disclosure Summary: The authors have nothing to disclose.

\section{References}

1. Heaton JM. The distribution of brown adipose tissue in the human. J Anat. 1972;112(Pt 1):35-39.

2. Nedergaard J, Bengtsson T, Cannon B. Unexpected evidence for active brown adipose tissue in adult humans. Am J Physiol Endocrinol Metab. 2007;293(2):E444-E452.

3. van Marken Lichtenbelt WD, Vanhommerig JW, Smulders NM, et al. Cold-activated brown adipose tissue in healthy men. $N$ Engl J Med. 2009;360(15):1500-1508.

4. Lidell ME, Betz MJ, Enerback S. Brown adipose tissue and its therapeutic potential. J Intern Med. 2014;276(4):364-377.

5. Cannon B, Nedergaard J. Brown adipose tissue: function and physiological significance. Physiol Rev. 2004;84(1):277-359.

6. Ricquier D, Nechad M, Mory G. Ultrastructural and biochemical characterization of human brown adipose tissue in pheochromocytoma. J Clin Endocrinol Metab. 1982;54(4):803-807.

7. Melicow MM. Hibernating fat and pheochromocytoma. AMA Arch Pathol. 1957;63(4):367-372.

8. Hadi M, Chen CC, Whatley M, Pacak K, Carrasquillo JA. Brown fat imaging with (18)F-6-fluorodopamine PET/CT, (18)F-FDG PET/ CT, and (123)I-MIBG SPECT: a study of patients being evaluated for pheochromocytoma. J Nucl Med. 2007;48(7):1077-1083.

9. Martinez-Sapina Llanas MJ, Romeu Vilar D, Jorge Mendez S, Alvarez Garcia A. Case 214: adrenal pheochromocytoma with perirenal brown fat stimulation. Radiology. 2015;274(2):617-621.

10. Park J, Byun BH, Jung CW, et al. Perirenal (18)F-FDG Uptake in a patient with a pheochromocytoma. Nucl Med Mol Imag. 2014; 48(3):233-236.

11. Seale P, Bjork B, Yang W, et al. PRDM16 controls a brown fat/ skeletal muscle switch. Nature. 2008;454(7207):961-967.

12. Wu J, Bostrom P, Sparks LM, et al. Beige adipocytes are a distinct type of thermogenic fat cell in mouse and human. Cell.2012;150(2): 366-376.

13. Di Franco A, Guasti D, Mazzanti B, et al. Dissecting the origin of inducible brown fat in adult humans through a novel adipose stem cell model from adipose tissue surrounding pheochromocytoma. J Clin Endocrinol Metab. 2014;99(10):E1903-E1912.

14. Gimenez-Roqueplo AP, Dahia PL, Robledo M. An update on the genetics of paraganglioma, pheochromocytoma, and associated hereditary syndromes. Horm Metab Res. 2012;44(5):328-333.

15. Eisenhofer G, Huynh TT, Pacak K, et al. Distinct gene expression profiles in norepinephrine- and epinephrine-producing hereditary and sporadic pheochromocytomas: activation of hypoxia-driven angiogenic pathways in von Hippel-Lindau syndrome. Endocr Relat Cancer. 2004;11(4):897-911.

16. Favier J, Briere JJ, Burnichon N, et al. The Warburg effect is genetically determined in inherited pheochromocytomas. PloS One. 2009;4(9):e7094.

17. Gimenez-Roqueplo AP, Favier J, Rustin P, et al. Functional consequences of a SDHB gene mutation in an apparently sporadic pheochromocytoma. J Clin Endocrinol Metab. 2002;87(10):47714774.

18. Rao JU, Engelke UF, Rodenburg RJ, et al. Genotype-specific abnormalities in mitochondrial function associate with distinct profiles of energy metabolism and catecholamine content in pheochromocytoma and paraganglioma. Clin Cancer Res. 2013;19(14): $3787-3795$.

19. Rao JU, Engelke UF, Sweep FC, et al. Genotype-specific differences in the tumor metabolite profile of pheochromocytoma and paraganglioma using untargeted and targeted metabolomics. J Clin Endocrinol Metab. 2015;100(2):E214-E222.

20. Jochmanova I, Yang C, Zhuang Z, Pacak K. Hypoxia-inducible factor signaling in pheochromocytoma: turning the rudder in the right direction. J Natl Cancer Inst. 2013;105(17):1270-1283.

21. Dahia PL, Familial Pheochromocytoma Consortium. Transcription association of VHL and SDH mutations link hypoxia and oxidoreductase signals in pheochromocytomas. Ann NY Acad Sci. 2006;1073:208-220.

22. Timmers HJ, Chen CC, Carrasquillo JA, et al. Comparison of 18Ffluoro-L-DOPA, 18F-fluoro-deoxyglucose, and $18 \mathrm{~F}$-fluorodopamine PET and 123I-MIBG scintigraphy in the localization of pheochromocytoma and paraganglioma. J Clin Endocrinol Metab. 2009; 94(12):4757-4767.

23. Pamporaki C, Bursztyn M, Reimann M, et al. Seasonal variation in plasma free normetanephrine concentrations: implications for bio- 
chemical diagnosis of pheochromocytoma. Eur J Endocrinol.2014; 170(3):349-357.

24. Eisenhofer G, Lattke P, Herberg M, et al. Reference intervals for plasma free metanephrines with an age adjustment for normetanephrine for optimized laboratory testing of phaeochromocytoma. Ann Clin Biochem. 2013;50(Pt 1):62-69.

25. van Berkel A, Rao JU, Kusters B, et al. Correlation between in vivo 18F-FDG PET and immunohistochemical markers of glucose uptake and metabolism in pheochromocytoma and paraganglioma. J Nucl Med. 2014;55(8):1253-1259.

26. Bauwens M, Wierts R, van Royen B, et al. Molecular imaging of brown adipose tissue in health and disease. Eur J Nucl Med Mol Imag. 2014;41(4):776-791.

27. Cypess AM, Lehman S, Williams G, et al. Identification and importance of brown adipose tissue in adult humans. N Engl J Med. 2009; 360(15):1509-1517.

28. Pfannenberg C, Werner MK, Ripkens S, et al. Impact of age on the relationships of brown adipose tissue with sex and adiposity in humans. Diabetes. 2010;59(7):1789-1793.

29. Perkins AC, Mshelia DS, Symonds ME, Sathekge M. Prevalence and pattern of brown adipose tissue distribution of 18F-FDG in patients undergoing PET-CT in a subtropical climatic zone. Nucl Med Commun. 2013;34(2):168-174.
30. Wang Q, Zhang M, Ning G, et al. Brown adipose tissue in humans is activated by elevated plasma catecholamines levels and is inversely related to central obesity. PloS One. 2011;6(6):e21006.

31. Tsujimoto G, Manger WM, Hoffman BB. Desensitization of $\beta$-adrenergic receptors by pheochromocytoma. Endocrinology. 1984; 114(4):1272-1278.

32. Giralt M, Villarroya F. White, brown, beige/brite: different adipose cells for different functions? Endocrinology. 2013;154(9):29923000 .

33. Lee P, Zhao JT, Swarbrick MM, et al. High prevalence of brown adipose tissue in adult humans. J Clin Endocrinol Metab. 2011; 96(8):2450-2455.

34. Warburg O. On the origin of cancer cells. Science. 1956;123(3191): 309-314.

35. Gottlieb E, Tomlinson IP. Mitochondrial tumour suppressors: a genetic and biochemical update. Nat Rev Cancer. 2005;5(11):857866.

36. Ma SW, Foster DO. Uptake of glucose and release of fatty acids and glycerol by rat brown adipose tissue in vivo. Can J Physiol Pharmacol. 1986;64(5):609-614.

37. Parysow O, Mollerach AM, Jager V, Racioppi S, San Roman J, Gerbaudo VH. Low-dose oral propranolol could reduce brown adipose tissue F-18 FDG uptake in patients undergoing PET scans. Clin Nucl Med. 2007;32(5):351-357. 